\title{
GPS Solutions
}

\section{Topo-Iberia Project: CGPS crustal velocity field in the Iberian Peninsula and Morocco. --Manuscript Draft--}

\begin{tabular}{|c|c|}
\hline Manuscript Number: & GPSS-D-14-00041 \\
\hline Full Title: & Topo-Iberia Project: CGPS crustal velocity field in the Iberian Peninsula and Morocco. \\
\hline Article Type: & Original Article \\
\hline Keywords: & GPS; Satellite Geodesy; Iberia Morocco Region; Tectonic Motion \\
\hline Corresponding Author: & $\begin{array}{l}\text { Jorge Garate, Ph.D. } \\
\text { Real Instituto y Observatorio de la Armada } \\
\text { San Fernando, Cadiz SPAIN }\end{array}$ \\
\hline \multicolumn{2}{|l|}{$\begin{array}{l}\text { Corresponding Author Secondary } \\
\text { Information: }\end{array}$} \\
\hline Corresponding Author's Institution: & Real Instituto y Observatorio de la Armada \\
\hline \multicolumn{2}{|l|}{$\begin{array}{l}\text { Corresponding Author's Secondary } \\
\text { Institution: }\end{array}$} \\
\hline \multicolumn{2}{|l|}{ First Author Secondary Information: } \\
\hline \multirow[t]{11}{*}{ Order of Authors: } & Jorge Garate, Ph.D. \\
\hline & Jose Martin Davila \\
\hline & Giorgi Khazaradze \\
\hline & Anna Echeverria \\
\hline & Eva Asensio \\
\hline & Antonio J. Gil \\
\hline & Concepcion Ayala \\
\hline & Gracia Rodriguez-Caderot \\
\hline & Jesus Galindo-Zaldivar \\
\hline & Abdelkrim Rimi \\
\hline & Mimoum Harnafi \\
\hline \multicolumn{2}{|c|}{ Order of Authors Secondary Information: } \\
\hline Abstract: & $\begin{array}{l}\text { A new Continuous GPS network was installed under the umbrella of a Research } \\
\text { Project called "Geociencias en Iberia: Estudios integrados de topografía y evolución } \\
\text { 4D (Topo-lberia)", to improve the understanding of the Iberian Peninsula region's } \\
\text { kinematic behavior. A brief description of this network is included. After a sufficient } \\
\text { span of years, data files collected at the new network stations were analyzed by three } \\
\text { different analysis groups contributing to the project. Different geodetic software } \\
\text { packages as well as different approaches were used to estimate a current crustal } \\
\text { deformation velocity field in the Iberian Peninsula and Morocco. In order to ensure the } \\
\text { consistency of the velocity fields determined by the three groups, the solutions } \\
\text { obtained by each Analysis Centre were transformed into a common Eurasia Reference } \\
\text { Frame. After that, the strain rate field was calculated. These strain rates are coherent }\end{array}$ \\
\hline
\end{tabular}


with the results obtained by other authors using different methodologies.

Powered by Editorial Manager ${ }^{\circledR}$ and ProduXion Manager ${ }^{\circledR}$ from Aries Systems Corporation 


\title{
Topo-Iberia Project: CGPS crustal velocity field in the Iberian Peninsula and Morocco.
}

\author{
J. Garate ${ }^{\mathrm{a}}$, J. Martin-Davila ${ }^{\mathrm{a}}$, G. Khazaradze ${ }^{\mathrm{b}}$, A. Echeverria ${ }^{\mathrm{b}}$, E. Asensio ${ }^{\mathrm{b}}$,A. J. \\ Gil $^{\text {c, d }}$, M. C. de Lacy ${ }^{\text {c, d }}$, J.A. García Armenteros ${ }^{\text {c, d }}$, A. M. Ruiz ${ }^{\text {c, d }}$, J. Gallastegui ${ }^{\mathrm{e}}$, \\ F. Alvarez-Lobato ${ }^{\mathrm{f}}$, C. Ayala ${ }^{\mathrm{g}}$, G. Rodríguez-Caderot ${ }^{\mathrm{h}}$, J. Galindo-Zaldívari, A. \\ Rimi $^{\mathrm{j}}$, Harnafi, M. ${ }^{\mathrm{j}}$ \\ ${ }^{a}$ Real Instituto y Observatorio de la Armada, 11100 San Fernando, Cádiz, Spain. \\ ${ }^{\mathrm{b}}$ Dpto. de Geodinámica i Geofísica, University of Barcelona, Spain. \\ ${ }^{\mathrm{c} D p t o}$. Ing. Cartográfica, Geodesia y Fotogrametría, University of Jaen, Spain. \\ ${ }^{\mathrm{d}}$ CEACTierra. Centro de Estudios Avanzados de Ciencias de la Tierra. Spain. \\ ${ }^{\text {e}}$ Dpto. de Geología, University of Oviedo, Spain. \\ ${ }^{\mathrm{f}}$ Dpto. de Geología, University of Salamanca, Spain. \\ ${ }^{g}$ Instituto Geológico y Minero de España. \\ ${ }^{\text {h}}$ Dpto. de Astronomía y Geodesia, Complutense University of Madrid, Spain. \\ ${ }^{i}$ Dpto. de Geodinámica. Universidad de Granada, Spain \\ ${ }^{\mathrm{j}}$ Institute Scientifique. Rabat, Morocco
}

\begin{abstract}
A new Continuous GPS network was installed under the umbrella of a Research Project called "Geociencias en Iberia: Estudios integrados de topografía y evolución 4D (Topo-Iberia)", to improve the understanding of the Iberian Peninsula region's kinematic behavior. A brief description of this network is included. After a sufficient span of years, data files collected at the new network stations were analyzed by three different analysis groups contributing to the project. Different geodetic software packages as well as different approaches were used to estimate a current crustal deformation velocity field in the Iberian Peninsula and Morocco. In order to ensure the consistency of the velocity fields determined by the three groups, the solutions obtained by each Analysis Centre were transformed into a common Eurasia Reference Frame. After that, the strain rate field was calculated. These strain rates are coherent with the results obtained by other authors using different methodologies.
\end{abstract}

\section{Keywords}

Satellite Geodesy; Iberia Morocco Region; Tectonic Motion

\section{Introduction}

The Iberian Peninsula and its continental margins is the geographical frame of the research initiative known as Topo-Iberia, funded by the Spanish Government through the Research project CSD2006-00041, named Geociencias en Iberia: Estudios integrados de topografía y evolución $4 D$ ('Topo-Iberia'). Developing and exploiting a new integrated database including geologic, seismic, geodetic and magnetoteluric observations, the project will produce a complete overview of interactions among deep, shallow and surface processes like tectonics, mass transport and landscape evolution. Three different areas well identified which can be found in the Peninsula: the northern edge, where the Pirenaic and Cantabric Mountain Systems are located; the plateau, as an intermediate central core, where the Iberic and the Central Cordilleras stand, and the southern edge, with the Betic mountains in Spain and the Rif Cordillera in Morocco. 


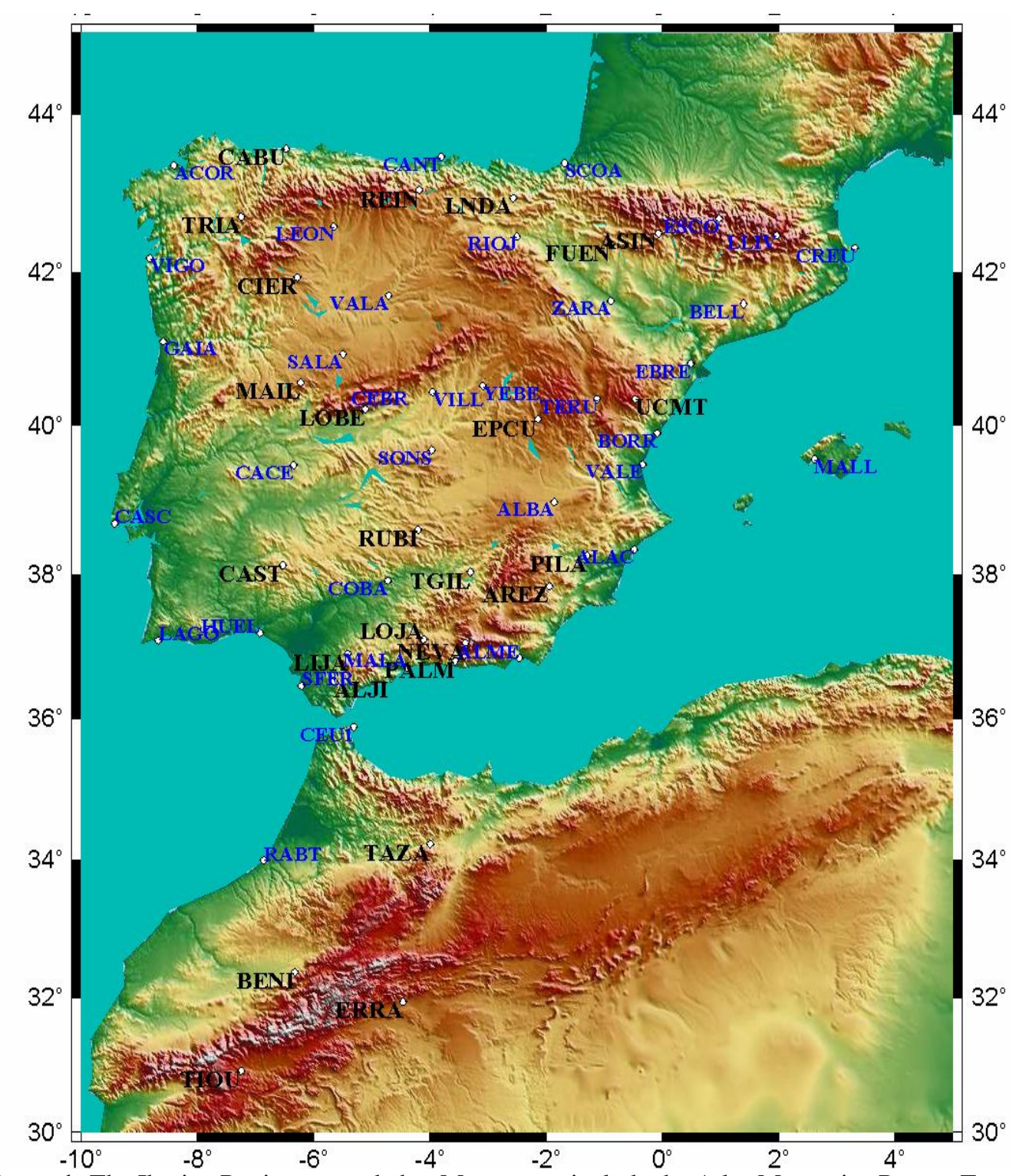

Figure 1: The Iberian Region, extended to Morocco to include the Atlas Mountains Range. TopoIberia CGPS Network stations (Black labels) and EUREF/IGS CGPS stations (blue labels) are shown in the region. Positions for the Topo-Iberia stations are shown in Annex I (Supplementary Material).

The geodetic contribution to the project, developed through the analysis of GPS permanent station data files, is considering the whole area of interest. A new CGPS network was designed and deployed, avoiding if possible the installation of the antennae over buildings in populated areas. Up to 26 new stations were installed to be included in the new network, four of them in Morocco. In order to optimize the network configuration, data files downloaded from already existing public GPS networks located in the region were used. Figure 1 shows the TopoIberia CGPS network and the additional CGPS stations used to derivate the regional geodetic behavior.

There are three GPS analysis groups evaluating the data files collected from the Topo-Iberia network as well as from the existing available GPS networks. Each one of these analysis groups works with different analysis software and uses different analysis strategies. The analysis team at San Fernando Naval 
Observatory (ROA) uses GIPSY-OASIS (Zumberge et al 1997), software developed at the Jet Propulsion Laboratory; the University of Barcelona (UB) works with GAMIT (Herring 2010), software developed at the Massachusetts Institute of Technology, and the analysis of the University of Jaen (UJA) working group is performed using the Bernese software (Datch et al., 2007). All of these are widely used throughout the geodetic community and their performances are well known. Comparisons of different solutions were carried out by some authors before now. Dietritch et al. (2001) analyzed planimetric and altimetric components, Kierulf et al. (2008) studied the vertical components and Avallone et al. (2010) compared horizontal components. The results show a very good agreement between the solutions, despite the differences in the processing strategies. Individual results as well as combined results among different solutions are shown in this paper, in the same way as (Kierulf et al., 2008).

The analysis strategy at ROA is based on the Precise Point Positioning (PPP) approach, while the analysis at UB and UJA is based on the traditional geodetic network solutions. The main difference between the two approaches is the way that the satellite and receiver clock errors are handled. PPP uses highly precise satellite clock estimates, while the network approach uses receiver differencing to remove both satellite and receiver clock errors. In order to obtain the satellite clock estimates, JPL analysts use a globally distributed network of CGPS receivers. The solution they obtained is issued at the JPL ftp server, and downloaded and used for all the groups working PPP with GIPSY. PPP also estimates receiver clocks behavior as part of the least squares solution for the coordinates. Then precise absolute coordinates for a single receiver located on an unknown point may be derived without using any other receiver at a known location (King et al., 2002).

In order to obtain velocity values for the points, position solutions aligned to the International Terrestrial Reference Frame (ITRF) time series are used. Since seasonal effects might introduce bias in the velocities, time series analysis must be performed. In accordance with (Blewitt and Lavallée, 2002) "only the annual and semiannual amplitudes and phases need to be estimated simultaneously along with velocity and initial position. However, estimation should only be applied for data spans $T>2.5$ years to avoid problems of correlated parameters and becomes rapidly unnecessary for $T>4.5$ years. In almost any realistic circumstance, estimation of annually repeating signals will dilute the precision by a negligible amount for $T>2.5$ years". Thus, the minimum data span we used for this study was 2.5 years, although in the most of the cases the suggested 4.5 years were completed, although gaps occurred in some stations, for different reasons. For instance, at the beginning of 2009 faults in the antennas were detected in some of the sites. As those antennas had to be replaced some jumps in the series were introduced. Several sites suffered vandalism attacks, for example stations REIN and VILA. For the former, the damages could be repaired. But the latter had to be dismantled. This is the reason why the results of VILA are not included in this paper

To compile more complete information about the behavior of the region, the previously ITRF aligned points were subsequently transformed to the European Reference Frame (ETRF), as defined by the European Permanent Network 
(Bruyninx, et al., 2009). Small deformations are easier to detect and to interpret in the regional frame than in the global one.

The network analyzed in this paper consists of about 60 CGPS stations located in the region, although the network analysis approaches use more than 100 CGPS to connect their solutions to the International References Frames. Permanent stations operated by different research institutions: IGS (http://igscb.jpl.nasa.gov), EUREF (http://www.epncb.oma.be) and other Spanish governmental as well as regional offices and private companies' CGPS data files were used along with the 26 CGPS stations strategically built in the Iberian Peninsula and in Northern Africa for the Topo-Iberia research project. The regional network we are showing includes data from all of these receivers. These 26 stations were all fully operational at the end of 2008.

Thus, the processed time-series, include four years of continuous data, long enough time-span to produce statistically significant results.

\section{GNSS data processing}

\subsection{Analysis at ROA using GIPSY-OASIS software}

The Precise Point Positioning (PPP) approach implemented in the GIPSY-OASIS software takes advantage of the large quantity of GPS stations observing the same set of satellites every day throughout the world. In such a way the JPL analysis center determines precise satellite positions and clock corrections from a globally distributed GPS receiver network. Daily files including satellite clock corrections and yaw angles are issued at the JPL ftp server together with the usual satellite orbits and earth orientation parameter information. Since all the data we use are calculated in a non-constrained, so-called free-network, transformation parameters to the ITRF realization must also be included. Once this orbital information is issued, data files from the local network are analyzed by estimating their own receiver parameters with their collected data, using those satellite parameters included in the downloaded files. Atmospheric zenith delay for each site was estimated, as well as the receiver clock biases. Absolute phase center variation for the antennae, both satellites and receivers, were introduced into the analysis by using the antex files issued by the International GNSS Service, for the corresponding ITRF realization. We used the GOT00.2_PP model for the oceanloading coefficients, calculated at the Onsala Space Observatory (Scherneck 1991). Since the beginning of April 2009 JPL has also produced new parameter files with information about wide-lanes and smoothed estimated phase biases from each GPS satellite to each one of the GPS receivers included in the abovementioned globally distributed network. These files will allow to the GIPSY software final users to derivate ambiguity solutions for single receiver data files analysis. Once the ambiguity fix solution is calculated, a final step has to be performed, applying a seven parameter transformation to this non constrained solution in order to align it with the ITRF, through the transformation file mentioned above. Formal errors are independent of the network from which global parameters were derived (Zumberge et al., 1997).

\begin{tabular}{|l|l|}
\hline Preprocessing & Not needed \\
\hline Basic Observable & $\begin{array}{l}\text { Carrier phase } \\
\text { Elevation angle cutoff: } 3 \text { degrees }\end{array}$ \\
\hline
\end{tabular}




\begin{tabular}{|l|l|}
\hline Modeled observable & Undifferenced ionosphere-free linear combination \\
\hline Data sampling & $300 \mathrm{sec}$ \\
\hline Earth geo-potential model & JGM3 \\
\hline Ocean loading model & GOT00.2_PP \\
\hline Atmospheric loading & not applied \\
\hline Solid Earth tides & IERS 2010 \\
\hline Orbits and ERPs & JPL final orbit and ERP information are adopted \\
\hline Planetary ephemeris & DE405s from JPL \\
\hline $\begin{array}{l}\text { Ground and satellite } \\
\text { antennae center calibration }\end{array}$ & $\begin{array}{l}\text { Absolute antenna phase center corrections based on } \\
\text { IGS08 model }\end{array}$ \\
\hline Troposphere & Niell Mapping functions \\
\hline Adjustment & $\begin{array}{l}\text { Precise Point Position, transformation parameters } \\
\text { from JPL }\end{array}$ \\
\hline Datum definition & Loosely constrained solution (10 m) \\
\hline Ambiguity & $\begin{array}{l}\text { Double differences of wide-lane and phase biases } \\
\text { estimates from the single receiver to all available } \\
\text { stations from network solution with common } \\
\text { satellites in view (>>2). Resolved ambiguities } \\
\text { introduced into final solution }\end{array}$ \\
\hline Satellite clock & $\begin{array}{l}\text { JPL final satellite clock biases information for PPP } \\
\text { processing }\end{array}$ \\
\hline Receiver clock & $\begin{array}{l}\text { Receiver clock corrections are estimated } \\
\text { simultaneously with station positions }\end{array}$ \\
\hline
\end{tabular}

Table 1: Characteristics of processing with GIPSY-OASIS

The biggest advantage of this approach is the speed of the analysis, as it does not need to combine baselines for the different stations included in the solution. It takes less than one minute to analyze a daily file for one station. Furthermore, if a new station has to be included in the solution after a first analysis, it is not necessary to repeat the whole network or sub-network calculation and adjustment. And errors in the analysis of the files of a station data do not contaminate the results for the neighbor stations analyzed.

Stacking daily position solutions produces time series for each one of the site coordinates, as shown in Figure 2 for LOJA horizontal coordinates. As a first approximation linear trends derived from coordinate time series generate velocities in the corresponding direction. But seasonal effects and eventual jumps in the series must be taken into account to obtain more accurate results. Furthermore, formal errors obtained from the raw time series are too optimistic, as they are treated only as white noise. A combination of white and flicker noise is more appropriate for most of the sites (Johnson and Agnew 1995; Zhang et al., 1997; Mao et al., 1999; Williams et al., 2004). After blunders were eliminated, time series were analyzed using the Create and Analyze Time Series (CATS) package (Williams et al., 2004). 


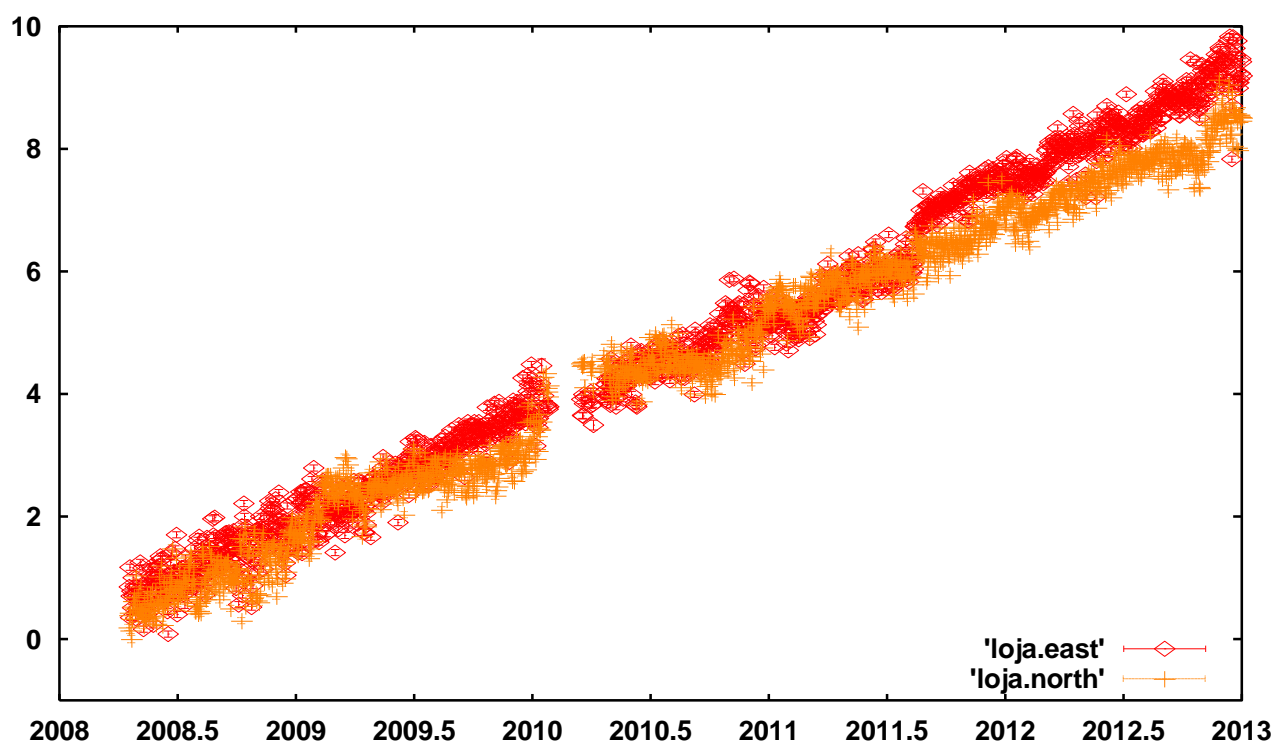

Figure 2: LOJA ITRF2008 East and North components raw time series for Loja calculated with GIPSY OASIS, as an example on how to obtain information on kinematic site behavior.

Jumps produced by CGPS stations configurations changes were corrected. Seasonal effects were also derived, by calculating annual and semiannual signals detected in the time series. Simultaneously, linear trends and offsets were obtained. Thus it is feasible to identify the trend with the site linear velocity. In addition, time series analysis software provides more realistic errors in the components than GIPSY-OASIS software output. Figure 2 shows the LOJA east and north coordinate time series. A rough approximation to the corresponding velocities is obtained by calculating the annual trends. A more accurate value is obtained by a further time series analysis.

Velocities, for the horizontal components in mm per year obtained at ROA, are shown in Annex II (Supplementary Material), after the CATS analysis where annual and semiannual effects were taken into account, as well as possible jumps in the time series.

\subsection{Analysis at the University of Jaen using Bernese and NEVE software}

In this study we processed independently with the same procedure two clusters of GPS data: one of them in the Iberian Peninsula from March 2008 to the end of 2012, and another one computed by the INGV in the European and Italian regions in the time span 1998-2012. This decision was taken in 2009 in order to obtain a set of fiducial stations which would be more stable due to the RING time series being longer. The data analysis was performed by the Bernese Processing Engine (BPE) of the software Bernese 5.0, using the options shown in Table 2. A previous check of the quality of data was carried out using the TEQC software developed by UNAVCO (Estey and Meertens 1999)

\begin{tabular}{|l|l|}
\hline Preprocessing & $\begin{array}{l}\text { Phase preprocessing in a baseline by baseline mode } \\
\text { using triple-differences. }\end{array}$ \\
\hline Basic Observable & $\begin{array}{l}\text { Carrier phase, code only used for receiver clock } \\
\text { synchronization. } \\
\text { Elevation angle cutoff: } 3 \text { degrees }+ \text { elevation }\end{array}$ \\
\hline
\end{tabular}




\begin{tabular}{|c|c|}
\hline & dependent weighting \\
\hline Modeled observable & ionosphere-free linear \\
\hline Data sampling & $30 \mathrm{sec}$ \\
\hline Earth geo-potential model & JGM3 \\
\hline Ocean loading model & FES2004 \\
\hline Ocean tides & OT_CSRC \\
\hline Atmospheric loading & not applied \\
\hline Solid Earth tides & applied, IERS Conventions96/2000 \\
\hline Orbits and ERPs & $\begin{array}{l}\text { IGS final orbit (Dow et al., 2009) and ERP } \\
\text { information are adopted }\end{array}$ \\
\hline Planetary ephemeris & DE200 from JPL \\
\hline $\begin{array}{l}\text { Ground and satellite } \\
\text { antennae center calibration }\end{array}$ & $\begin{array}{l}\text { Absolute antenna phase center corrections based on } \\
\text { IGS05 model }\end{array}$ \\
\hline Troposphere & $\begin{array}{l}\text { Dry-Niell as a priori model, estimation of zenith } \\
\text { delay corrections at 2-hour intervals for each station, } \\
\text { using the wet-Niell MF, no a priori sigma. } \\
\text { Horizontal gradient parameter estimated/day/station } \\
\text { (TILTING), no a priori constraints. }\end{array}$ \\
\hline Adjustment & $\begin{array}{l}\text { Weighted least-squares algorithm with correct } \\
\text { correlations }\end{array}$ \\
\hline Datum definition & Loosely constrained solution $(10 \mathrm{~m})$ \\
\hline Ambiguity & $\begin{array}{l}\text { QIF strategy to resolve ambiguities for each baseline. } \\
\text { Resolved ambiguities introduced into final solution }\end{array}$ \\
\hline Satellite clock & $\begin{array}{l}\text { Satellite clock biases are not estimated but bias } \\
\text { eliminated by forming double-differences }\end{array}$ \\
\hline Receiver clock & $\begin{array}{l}\text { Receiver clock corrections are estimated during the } \\
\text { bias pre-processing using code measurements }\end{array}$ \\
\hline
\end{tabular}

Table 2. Characteristics of processing with Bernese Software

We have estimated one daily solution in a loosely constrained reference frame, close to the rank deficiency condition. The output file is composed of the coordinates of the stations along with their covariance matrix in SINEX format. Loosely constrained solutions can be combined regardless of the datum definition of each contributing solution. The solution reference frame is defined stochastically by the input data and is basically unknown, but it is not necessary to estimate or to apply relative rigid transformations (rotation-translation-scale) between reference frames and this naturally leads to a combined solution not distorted by any constrain or transformation. Therefore, our daily loosely constrained cluster solutions are then merged into global daily loosely constrained solutions of the whole network, applying a classical least squares approach where the mathematical model is defined by the time propagation operator (Bianco et al., 2003). After that, the daily combined network solutions are minimally constrained and transformed into the ITRF2005 frame, estimating translations and scale parameters. In particular the realization EPN_A_ITRF2005 was used and 13 core stations contributed to the rigid transformation. These stations were AJAC, BOR1, BUCU, CAGL, EBRE, GRAS, GRAZ, LAMP, MATE, NOT1, SFER, SJDV and ZIMM.

We estimated the velocity field by using purposely designed software (NEVE) that manages the complete stochastic model (Devoti et al., 2008; Devoti et al., 
2011). Velocities were estimated simultaneously, together with annual signals and sporadic offsets at epochs of instrumental changes. The velocity field was estimated from ITRF2005 time series of daily coordinates with the complete covariance matrix. Velocity errors were derived from the direct propagation of the daily covariance matrix. Velocities for the horizontal components in mm per year obtained at UJA, are shown in Annex II (Supplementary Material).

\subsection{Analysis at University of Barcelona (UB) using GAMIT/GLOBK}

The University of Barcelona group (UB) analyzed data using GAMIT/GLOBK software (Herring et al. 2010) from the MIT that uses double differences of the phase and code data on the ionosphere-free LC combination to compute a network solution. We followed a three-step approach similar to the one described by McClusky et al. (2000). Previous to these steps, we performed a quality check of the analyzed stations, which included the examination of their monumentation, availability of the uninterrupted data, a presence of correct information on the antenna and hardware changes in the log-files provided. In order to examine the quality of the actual GPS data given in daily RINEX files we used the TEQC software from UNAVCO (Estey and Meertens, 1999).

\begin{tabular}{|l|l|}
\hline Preprocessing & Quality check of the data using the TEQC program. \\
\hline Basic Observable & $\begin{array}{l}\text { Doubly differenced, ionosphere-free combination of } \\
\text { L1 and L2 carrier phases. Pseudoranges are used } \\
\text { only to obtain receiver clock offsets and in ambiguity } \\
\text { resolution. }\end{array}$ \\
\hline Modeled observable & $\begin{array}{l}\text { Double-differenced carrier phase with ionosphere- } \\
\text { free linear combination. Clocks are estimated in a } \\
\text { post-processing step using one-way observables with } \\
\text { the ensemble mean of the clock residuals at a set of } \\
\text { reference ground stations set to zero at each epoch. }\end{array}$ \\
\hline Data sampling & 30 sec \\
\hline Earth geo-potential model & $\begin{array}{l}\text { EGM96 degree and order 9; C21 \& S21 modeled } \\
\text { according to polar motion variations. }\end{array}$ \\
\hline Ocean loading model & Applied using model FES2004 \\
\hline Ocean tides & Applied using model FES2004 \\
\hline Atmospheric loading & Not applied \\
\hline Solid Earth tides & applied, IERS03 \\
\hline Orbits and ERPs & IGS final orbit and ERP information are adopted. \\
\hline Planetary ephemeris & Generated from the MIT PEP program. \\
\hline $\begin{array}{l}\text { Ground and } \\
\text { antennae center calibration }\end{array}$ & $\begin{array}{l}\text { Absolute antenna phase center corrections based on } \\
\text { IGS08 model. }\end{array}$ \\
\hline Troposphere & $\begin{array}{l}\text { Zenith delay: residual delays are adjusted for each } \\
\text { station assuming they are mostly dominated by the } \\
\text { "wet" component; parameterized by piecewise linear, } \\
\text { continuous model with 2-hr intervals } \\
\text { Mapping function: GMF (Boehm et al., 2006) wet } \\
\text { function used to estimate zenith delay residuals. }\end{array}$ \\
\hline Adjustment & $\begin{array}{l}\text { Weighted least squares to generate loosely } \\
\text { constrained covariance matrices and solutions that } \\
\text { are passed through a Kalman filter for network }\end{array}$ \\
\hline
\end{tabular}




\begin{tabular}{|l|l|}
\hline & combinations. \\
\hline Datum definition & Loosely constrained solution (10 m) \\
\hline Ambiguity & $\begin{array}{l}\text { Adjusted, using real-valued double-differenced } \\
\text { phase cycle ambiguities. }\end{array}$ \\
\hline Satellite clocks & $\begin{array}{l}\text { Estimated using one-way phase data aligned with } \\
\text { pseudorange. Clock estimation is completed after } \\
\text { orbits and station coordinates for a week of data have } \\
\text { been determined. }\end{array}$ \\
\hline Receiver clocks & $\begin{array}{l}\text { Estimated. Station clocks except the reference clock } \\
\text { station are decimated to 300 seconds. }\end{array}$ \\
\hline
\end{tabular}

Table 3: GAMIT/GLOBK processing characteristics at the UB.

In the first step of our data analysis, we used daily GPS observations to estimate station coordinates together with estimates of the zenith delay of the atmosphere at each station. Orbital and Earth Orientation Parameters (EOP) were held fixed to the IGS final values by using a BASELINE mode. In the second step we used these loosely constrained solutions to estimate consistent coordinates of the stations using the data combinations with the GLRED module of the GLOBK package. Afterwards we examined the time series of all the stations and removed obvious outliers following two criteria: if the position errors were higher than 20 $\mathrm{mm}$ and if the position itself was displaced more than $10 \mathrm{~mm}$ away from the best fitting trend line. Furthermore, some stations required offset corrections due to antenna changes. These steps were performed using several C-shell scripts specifically designed for this task, as well as, using interactive MATLAB ${ }^{\circledR}$ tools for viewing GPS velocities and time series developed by Herring (2003). Finally, the $\mathrm{S}$ solution was realized in the ITRF2008 global reference frame (Altamimi et al., 2011), by minimizing the differences (using Helmert transformation) between our estimated horizontal velocities for the reference stations that have velocities computed in ITRF2008. The step of converting the ITRF2008 velocities into a Eurasia fixed reference frame is described in the next section. The results in this reference frame are displayed in the table included in Annex II (Supplementary Material). Figure 3 shows the results obtained for the three analysis groups in the International Terrestrial Reference Frame.

\section{Velocity solutions in the European Terrestrial Reference Frame (ETRF)}

The ITRF velocity field maps are not well tuned to give an easy overview and interpretation of the tectonic behavior of the study area. Coordinates and velocities have to be transformed to a regional reference frame to produce a velocity field, which may be understood more easily. This is done by applying a 14 parameter Helmert transformation. But this set of parameters should be derived also, by including in our analysis points whose position and velocities are shown in the published Regional Reference Frame. In this analysis we used a set of about 30 CGPS stations included in the European Permanent Networks and located in this region, so their position and velocities with respect to the European Terrestrial Reference Frame are well known. Using them as fiduciary points, the transformation parameters could be obtained. As an alternative method to using the calculated 14 parameters transformation, the ROA analysis group performed the seven parameters Helmert transformation on a daily basis, i.e., the 
transformation was applied to each individual daily solution for every station analyzed.

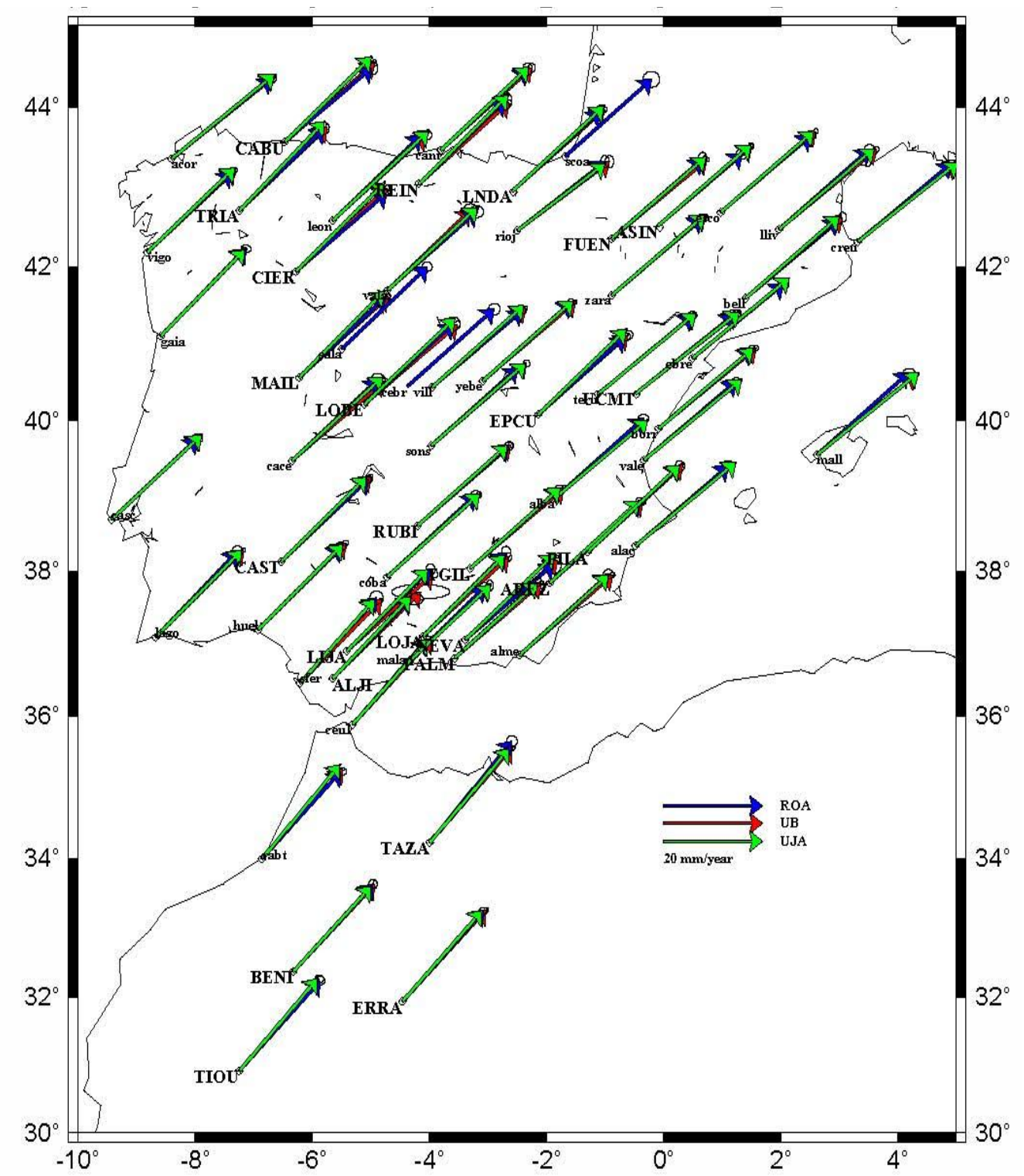

Figure 3:Topo-Iberia network velocities in the ITRF reference frame. The three different analysis groups derived these velocities from position time series. ROA (blue) and UB (red) solutions are in ITRF2008, while UJAEN (green) solution is in ITRF2005. As solutions are quite similar, some arrows seem to be hidden by the other analysis group results. Values can be found in TableA2 included in Annex II (Supplementary Material).

In this way we obtained new time series that were analyzed with CATS software as well, in order to obtain the more accurate regional solution. Horizontal velocity components are shown in Table A3 included as Annex III (Supplementary Material). All the site velocities are referred to the ETRF2000 reference frame. Those calculated at ROA are presented after CATS analysis, including again annual and semiannual seasonal signals, as well as the effects of the jumps over the time series.

The UJA group transformed the ITRF2005 solutions into the Eurasian Reference Frame using the Euler pole of the Eurasian plate published by Altamimi et al. 
(2007). Specifically, the Euler pole parameters employed were: $56.33^{\circ} \mathrm{N}, 95.98^{\circ} \mathrm{W}$ and $0.261 \pm 0.003^{\circ} / \mathrm{Myr}$.

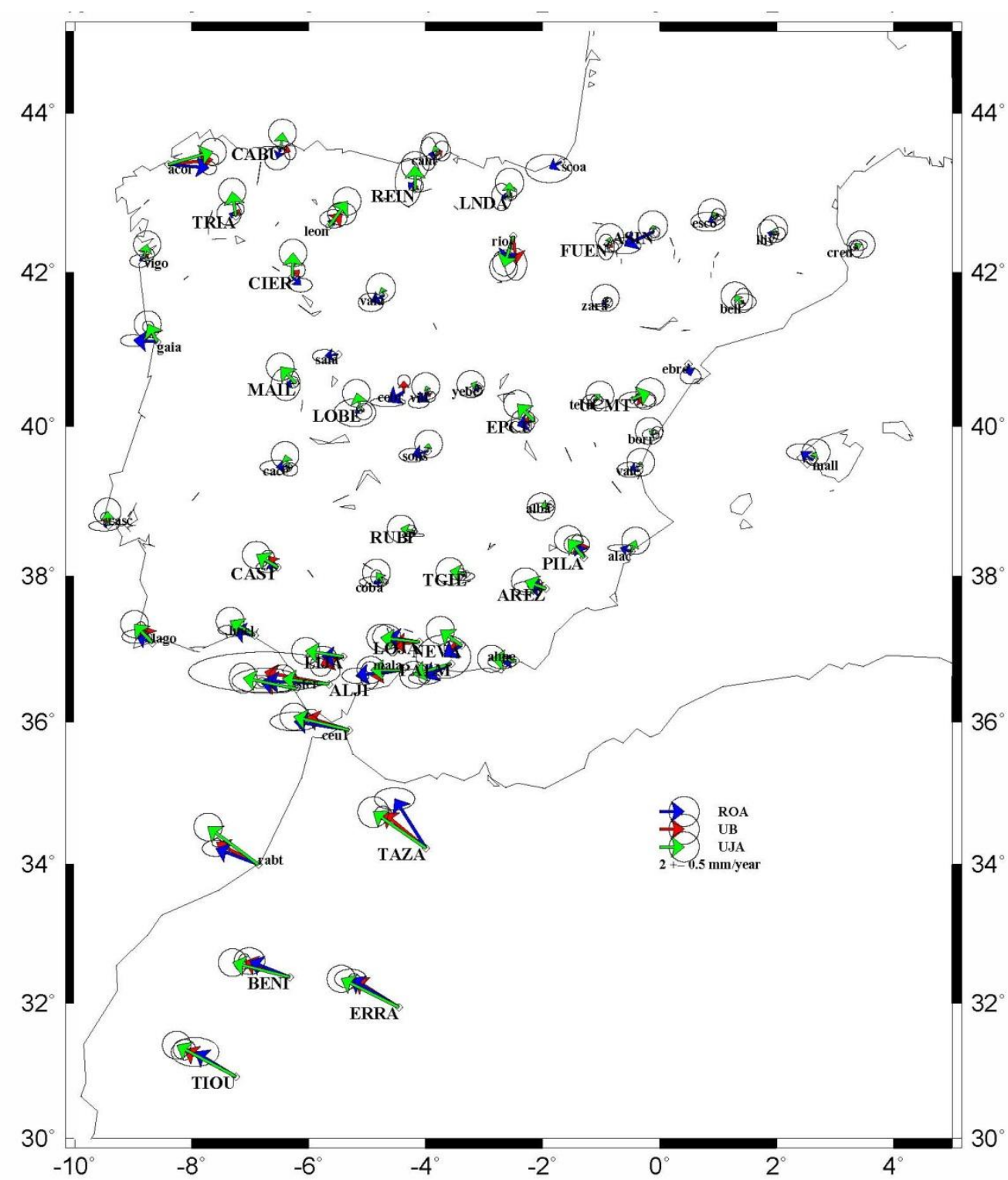

Figure 4: ETRF2000 velocities derived from position time series produced by GIPSY OASIS software after time series analysis with CATS (blue arrows); GAMIT/GLOBAK at UB (red arrows); and Bernese and NEVE at UJA (green arrows).

The UB group resorted to a somewhat different approach in order to estimate the Eurasia fixed reference frame. They estimated the Euler pole of the Eurasian plate and transformed the ITRF2008 solutions into the Eurasian Reference Frame. To calculate the Euler Pole, different groups of reference CGPS stations defining the Eurasian Reference Frame were used. As a selection criterion we chose the maximum horizontal residual velocity of $0.3 \mathrm{~mm} / \mathrm{yr}$, which provided us with a set of ten sites that define a fixed Eurasia. 
However, since the three analysis groups used somewhat different procedures to transform the ITRF velocities to the ETRF reference frame, we performed the unification of the 3 velocity solutions, as described below.

\subsection{Combination}

In order to ensure the consistency of the velocity fields determined by the three groups, we transformed the ITRF solutions of each group to a common Eurasia Feference Frame. The latter was defined using the three Cartesian components of the Eurasia Euler pole ( $w x=-0.021890 ; w y=-0.147500 ; w z=0.213100$ in $\mathrm{deg} / \mathrm{Myr}$ ), as defined by the ITRF2008 (Altamini et al., 2011). The transformation was performed using the VELROT V1.01 velocity field comparison and combination software included in the GLOBK/GAMIT analysis package (Herring et al. 2010). As a result of a 6-parameter transformation (translational and rotation), we obtained the three consistent solutions in the Eurasia fixed ITRF2008 frame for the 25 Topo-Iberia stations (Figure 5a)).

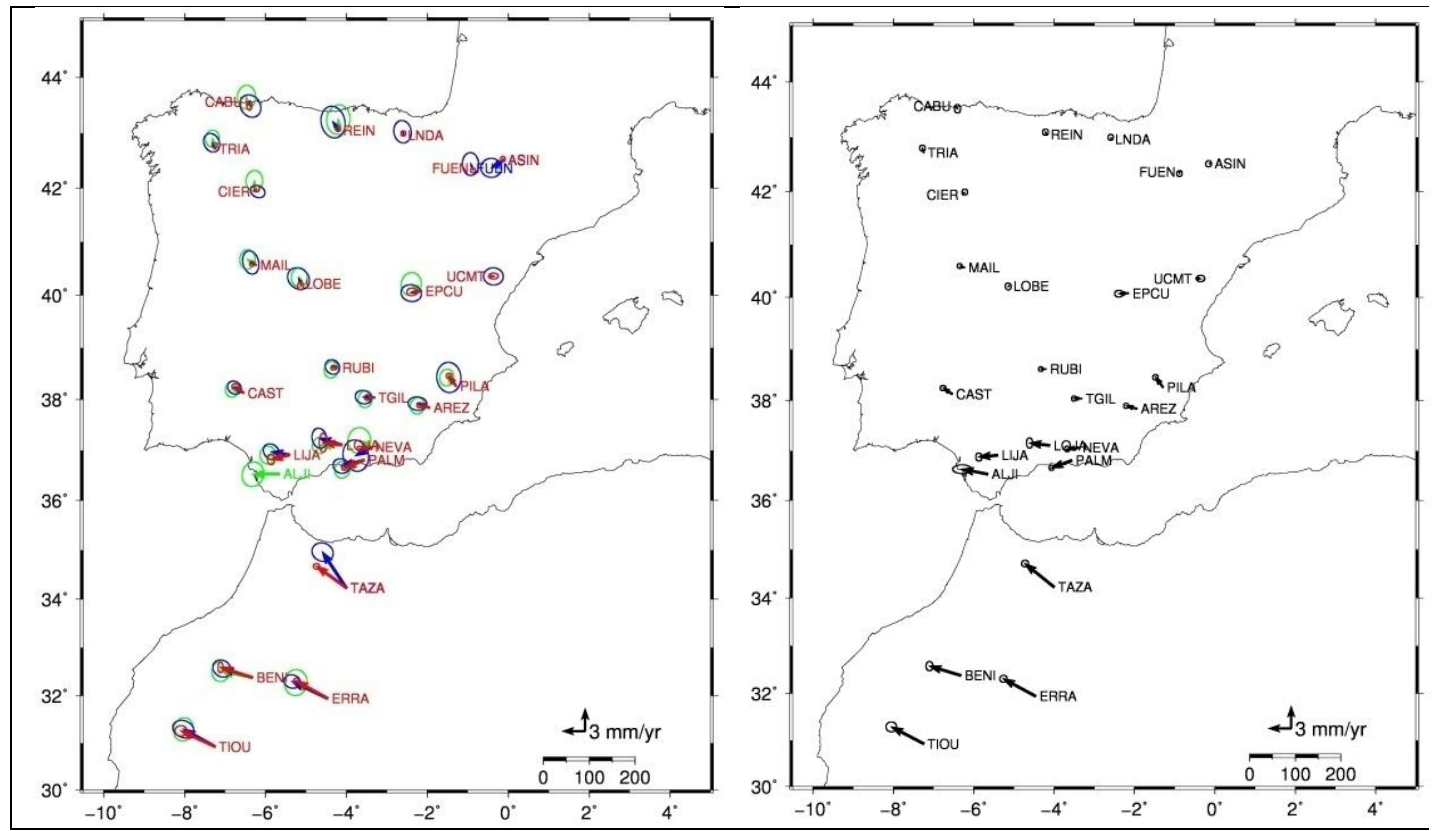

Figure 5: a) Eurasia fixed velocities derived from VELROT transformations. ROA: (blue); UB (red); UJA (green). b) Average velocity field of the Topo-Iberia GPS network in Eurasia fixed ITRF2008 reference frame. This was obtained from the combination of the three solutions from ROA, UB and UJA.

Comparing the transformed solutions to the individual solutions presented in the previous section (Figure 4), it is possible to note that after the combination procedure was performed the velocities estimated by the three groups were considerably more consistent with each other. For example, a northward motion observed in the UJA estimated velocities for the stations CABU, REIN and LNDA (see green vectors in Figure 4) is not visible any more.

At a final stage of the combination we used the VELROT program to calculate an average velocity field from the three solutions for the 25 stations of the TopoIberia network. These results are shown in Table 4 and Figure 5b. Results for the other CGPS stations in the area but also for the EUREF stations fixed to make the transformation from the ITRF to the ETRF are shown in Table A3, included in Annex III (Supplementary Material). 


\begin{tabular}{|c|l|c|c|}
\hline$\#$ & $\begin{array}{c}\text { STA } \\
\text { ID }\end{array}$ & East $\pm \mathbf{1} \boldsymbol{\sigma}$ & North $\pm \mathbf{1} \boldsymbol{\sigma}$ \\
\hline 1 & ALJI & $-3.45 \pm 0.10$ & $0.05 \pm 0.09$ \\
\hline 2 & AREZ & $-1.56 \pm 0.06$ & $0.26 \pm 0.07$ \\
\hline 3 & ASIN & $-0.27 \pm 0.12$ & $-0.04 \pm 0.13$ \\
\hline 4 & BENI & $-4.08 \pm 0.10$ & $0.96 \pm 0.11$ \\
\hline 5 & CABU & $0.17 \pm 0.08$ & $0.25 \pm 0.10$ \\
\hline 6 & CAST & $-1.41 \pm 0.06$ & $0.53 \pm 0.07$ \\
\hline 7 & CIER & $0.18 \pm 0.07$ & $1.02 \pm 0.08$ \\
\hline 8 & EPCU & $-1.32 \pm 0.08$ & $0.64 \pm 0.08$ \\
\hline 9 & ERRA & $-4.19 \pm 0.11$ & $2.19 \pm 0.11$ \\
\hline 10 & FUEN & $0.02 \pm 0.10$ & $-0.14 \pm 0.11$ \\
\hline 11 & LIJA & $-2.73 \pm 0.07$ & $-0.04 \pm 0.08$ \\
\hline 12 & LNDA & $-0.04 \pm 0.10$ & $0.36 \pm 0.12$ \\
\hline 13 & LOBE & $-0.21 \pm 0.07$ & $0.63 \pm 0.07$ \\
\hline 14 & LOJA & $-2.87 \pm 0.06$ & $-0.08 \pm 0.07$ \\
\hline 15 & MAIL & $-0.98 \pm 0.07$ & $0.56 \pm 0.07$ \\
\hline 16 & NEVA & $-1.51 \pm 0.08$ & $0.48 \pm 0.09$ \\
\hline 17 & PALM & $-2.79 \pm 0.07$ & $-1.23 \pm 0.07$ \\
\hline 18 & PILA & $-1.19 \pm 0.06$ & $1.16 \pm 0.07$ \\
\hline 19 & REIN & $-0.10 \pm 0.08$ & $0.96 \pm 0.10$ \\
\hline 20 & RUBI & $-0.86 \pm 0.06$ & $-0.23 \pm 0.06$ \\
\hline 21 & TAZA & $-3.87 \pm 0.15$ & $2.96 \pm 0.15$ \\
\hline 22 & TGIL & $-1.17 \pm 0.06$ & $-0.18 \pm 0.07$ \\
\hline 23 & TIOU & $-4.12 \pm 0.13$ & $2.28 \pm 0.13$ \\
\hline 24 & TRIA & $-0.23 \pm 0.07$ & $1.07 \pm 0.07$ \\
\hline 25 & UCMT & $1.20 \pm 0.12$ & $0.04 \pm 0.11$ \\
\hline
\end{tabular}

Table 4: Topo-Iberia GPS Network combined velocities (mm/yr) with their standard deviations in the ETRF Frame. ASCII format file to be used in GMT psvelo routine is provided as a supplementary material.

\section{Discussion}

Starting in the Pyrenees mountain belt in the north (Asensio et al., 2012), which separates the Iberian Peninsula from the rest of the European continent, and going to the south, the majority of the observed points show very small velocity residuals with respect to the ETRF. There are some exceptions though: stations ACOR and RIOJ. The latter is most probably due to the problem reported in the receiver, and the behavior of the former is more difficult to explain, but most likely it is due to the monument and/or building instability. However, in the southern-most part of the Iberian Peninsula the residual motions become more prominent. This is not surprising, since this part includes a plate boundary zone 
that accommodates approximately $5 \mathrm{~mm} / \mathrm{yr}$ relative motion between the Eurasian and Nubian tectonic plates (McClusky et al., 2003). The largest velocities are observed for the stations located in Morocco, since these points are no longer located on the Eurasian plate but instead belong to the Nubian tectonic plate.

\subsection{Strain Rate Calculation}

At the initial stage strain rate parameters were calculated for all the processed stations within the study area: Iberia and North Africa. However, since the spatial coverage of the stations in north Africa was limited (only 5 stations were processed), the results were statistically insignificant, and for this reason we concentrated on the analysis of the 55 CGPS stations from the Iberian Peninsula, which included the 25 Topo-Iberia stations. The strain rate field calculation was performed using the SSPX software package (Cardozo and Allmendinger, 2009). We used the grid-nearest neighbor approach that computes strain rate at the center of each square. The following optimal parameters were chosen for the strain calculation: a grid spacing of $70 \mathrm{~km}$ and the 7 nearest stations located within a maximum distance of $200 \mathrm{~km}$. These parameters provide a smoothed regional pattern, and some local strain field variations could have been missed. The horizontal principal strain rate axes and dilatation are shown in Figure 6a). Figure 6b) shows maximum shear strain rates and the direction of left-lateral motion. The right-lateral motion would be oriented perpendicular to the shown direction. In all cases only statistically significant values at $1 \sigma$ level are presented. Positive dilatational strain rates in Figure 6 a), shown in red colors, indicate extension, while negative values, shown in blue, indicate compression.

It can be appreciated that the maximum deformation signal is observed in the central Betics and northern Alboran Sea. Here both the dilatation and the shear strain rates reach their maximum values: WSW-ENE extension of approximately 30 nstrain/yr (Figure 6a) and shear strain rate (Figure 6b)) of 25 nstrain/yr oriented approximately WSE-NNW for the left-lateral shear (green axis). The central Betic zone is known for its high rate of seismicity. In 1910 a $\mathbf{M}_{w} 6.1$ earthquake occurred near the city of Adra, which had an oblique-strike-slip focal mechanism (Stich et al., 2003), roughly in agreement with the strain-rate direction estimated from the GPS velocities. Moreover, previous geodetic studies showed that the Balanegra fault, located just east of Adra, exhibits an uplift rate between 0.09 to $0.12 \mathrm{~mm} / \mathrm{yr}$, indicating a horizontal WSW-ESE regional extension (e.g. Marín-Lechado et al., 2010).

A small region of high shear strain rate is observed in the east-central part of the peninsula, near Alicante. This highly deforming zone is most likely related to the Crevillente (or Cadiz-Alicante) fault system, which causes a westward displacement of the Betic Internal Zone and part of the External Zone (e.g. Sanz de Galdeano and Buforn, 2005). Part of the strain in the region can be attributed 
to the Alhama de Murcia fault (Echeverria et al., 2013), that was responsible for the $\mathrm{M}_{\mathrm{w}} 5.2$ 11/05/2011 Lorca earthquake (Frontera et al., 2012; Martínez-Díaz et al., 2012). However, with the given spatial coverage it might be a bit hasty to unambiguously attribute the observed shear strain rates to the Crevillente fault system.
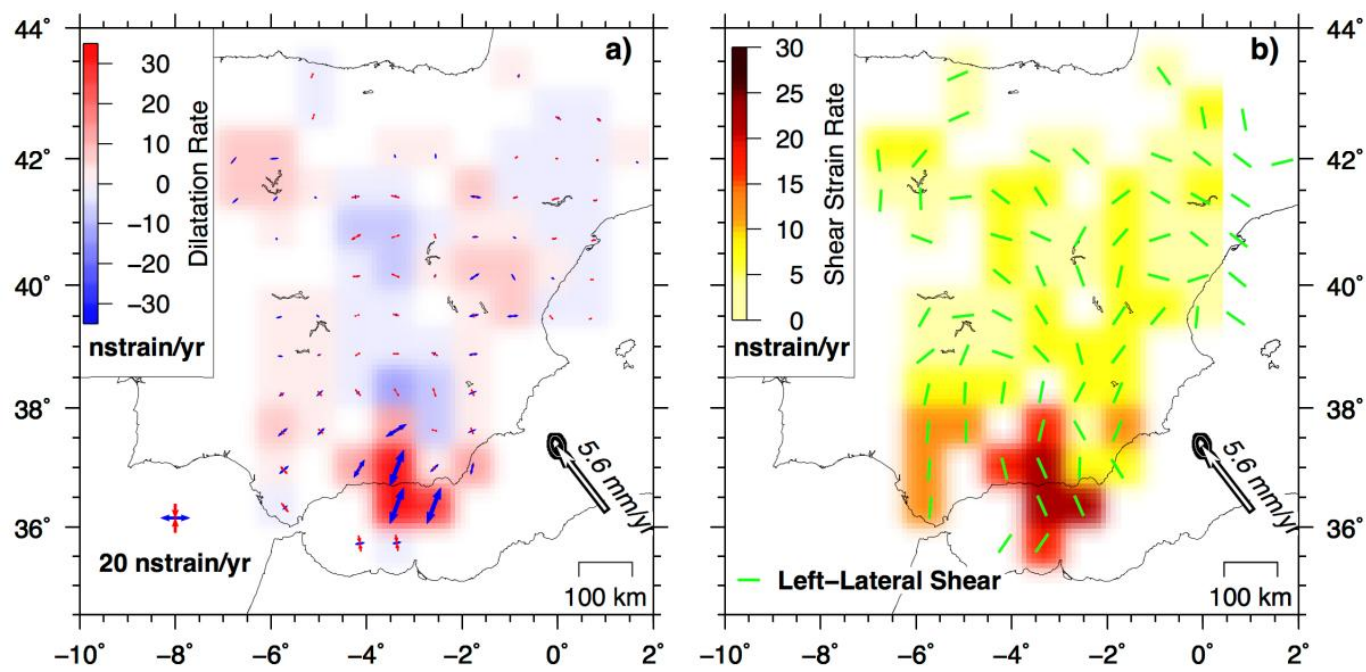

Figure 6: GPS strain rate field computed for the Iberian Peninsula. The calculations were performed with the SSPX software (Cardozo and Allmendinger, 2009) using the $70 \mathrm{~km}$ grid spacing for the 7 nearest neighbors up to a maximum distance of $200 \mathrm{~km}$. Only statistically significant values at $1 \sigma$ level are plotted. a) 2D dilatation strain rates: blue is compression; red is extension. The blue axis indicates a direction of extension and the red axis a direction of compression; b) Maximum shear strain rates. The color scale indicates the magnitude of the maximum shear strain rate. Green lines in the middle of the grid indicate the maximum sinistral shear directions.

Strain rate calculations are also in agreement with results previously published by Perez-Peña et al. (2010). Although the methodologies used in the two studies to calculate the strain rates were different (Perez-Peña used Delaunay triangulation), the results are coherent. Similarly, our results agree with those presented by Fadil et al. (2006), although their deformation rates are somewhat higher and located farther to the south in the Alboran Sea, probably due to the utilization of a denser data set from Morocco.

Another deformation focus based on our calculations is located around the Strait of Gibraltar and the Gulf of Cadiz (blue boxes in Figure 5a). Here we observe negative dilatation rates of 4 nstrain/yr indicating a compression oriented WNWESE, in agreement with the orientation of the maximum contractional-horizontal strain-rate estimated by Palano et al. (2013).

When talking about strain rates we found a maximum strain rate offshore at the Alboran Sea to the south of the Betics. Another maximum was found close to the 
Gulf of Cadiz. This pattern is quite similar to the strain rates of Palano et al. (2013), although the magnitudes are slightly different. As expected, the estimated strain rates decrease to the north, where the deformation rates are smaller.

\section{Conclusions}

In the framework of the Topo-Iberia project we have established a geodetic network of 25 continually operating GPS stations, located in Spain (21 stations) and Morocco (4 stations). Considerable financial and human resources were dedicated to a correct design and monumentation of the network, which took the first 2 years of the project. Since the main goal behind the establishment of the Topo-Iberia GPS network was the detection of relatively slow (less then 5 $\mathrm{mm} / \mathrm{yr}$ ) tectonic deformations throughout the Iberian Peninsula and northern Africa, we have ensured that the geodetic monuments were stable and the detected velocities were indeed related to the long-term geologic and tectonic motions.

More specifically, through an increased spatial coverage of the CGPS stations and state-of-the-art analysis procedure, we have been able to provide a contemporary crustal deformation velocity field for the Iberian Peninsula and Morocco with an unprecedented precision. As can be seen from Figure 5 and Table 4 maximum horizontal velocities (in the Eurasia frame) are observed for the stations located on the Africa (i.e. Nubia) tectonic plate in Morocco, where the calculated velocities range from 4.2 to $4.9 \mathrm{~mm} / \mathrm{yr}$. Within the Iberian Peninsula, as mentioned earlier, maximum velocities are observed in the southern margin, close to the Straight of Gibraltar and the Betics. Here the velocities reach $3.5 \mathrm{~mm} / \mathrm{yr}$ at station ALJI, indicating that the tectonic behavior of this region is influenced more by the African plate than the Eurasian. The estimated $1 \sigma$ uncertainties for the calculated velocities are low: they are all below $0.2 \mathrm{~mm} / \mathrm{yr}$.

To conclude, one the main achievements of the Topo-Iberia GPS project can be considered the establishment of the highly-stable network of the CGPS stations in Spain and Morocco. Currently we are in the process of incorporating this network into the European Plate Observing System (EPOS), an integrated solid earth sciences research infrastructure included in the ESFRI Roadmap in December 2008 (www.epos-eu.org). As a result, we hope that the entire TopoIberia network will continue its operation and that the data will become available to a wide range of users which will not be limited to scientists studying earthquakes and tectonics, but will include practitioners of geodesy and climate research.

\section{Acknowledgements}

This research has been funded by the Ministry of Science and Innovation of Spain through the research project "Geosciences in Iberia: Integrated studies on topography and 4-D evolution" (CSD2006-00041). 
We would like to express our gratitude to all those people, representing various institutions, who participated in searching for appropriate site locations, and their consequent installation and operation. Also, we would like to thank the landowners (e.g. city and village councils), who gave their generous permission to install the valuable scientific equipment on their properties.

Most of the figures were prepared using the public domain Generic Mapping Tools GMT (Wessel et al., 2013). 


\section{References}

Altamimi, Z., Collilieux, X., Legrand, J., Garayt, B., Boucher, C., 2007. ITRF2005: A new release of the International Terrestrial Reference Frame based on time series of station positions and Earth Orientation Parameters. J. Geophys. Res. 112, B09401, doi: 10.1029/2007JB004949.

Altamini, Z., Collilieux, X., Métivier, L., 2011. ITRF2008: An improved solution of the international terrestrial reference frame. J. Geod. 85, 457-473, doi: 10.1007/s00190-011-0444-4.

Asensio, E., Khazaradze, G., Echeverria, A., King, R.W., Vilajosana, I., 2012. GPS studies of active deformation in the Pyrenees. Geophys. J. Int. 190, 913-921, doi: 10.1111/j.1365246X.2012.05525.x.

Avallone, A., Selvaggi, G., D’Anastasio, E., D’Agostino, N., Pietrantonio, G., Riguzzi, F., Serpelloni, E., Anzidei, M., Casula, G., Cecere, G., D\&\#039;Ambrosio, C., De Martino, P., Devoti, R., Falco, L., Mattia, M., Rossi, M., Obrizzo, F., Tammaro, U., Zarrilli, L., D’Ambrosio, C., 2010. The RING network: improvement of a GPS velocity field in the central Mediterranean. Ann. Geophys. 53, 39-54, doi: 10.4401/ag-4549.

Bianco, G., Devoti, R., Luceri, V., 2003. Combination of loosely constrained solutions, in: Proceedings of the IERS Workshop on Combination Research and Global Geophysical Fluids, Edited by B. Richter, W. Schwegmann, and WR Dick. pp. 107-109.

Blewitt, G., Lavallée, D., 2002. Effect of annual signals on geodetic velocity. J. Geophys. Res. 107, 1-9, doi: 10.1029/2001JB000570.

Boehm, J., Niell, A., Tregoning, P., Schuh, H., 2006. Global Mapping Function (GMF): A new empirical mapping function based on numerical weather model data. Geophys. Res. Lett. 33, L07304, doi: 10.1029/2005GL025546.

Bruyninx, C., Altamimi, Z., Boucher, C., Brockmann, E., Caporali, A., Gurtner, W., Habrich, H., Hornik, H., Ihde, J., Kenyeres, A., Mäkinen, J., Stangl, G., Marel, H., Simek, J., Söhne, W., Torres, J.A., Weber, G., 2009. The European Reference Frame: Maintenance and Products, in: Drewes, H. (Ed.), Geodetic Reference Frames. Springer Berlin Heidelberg, pp. 131-136.

Cardozo, N., Allmendinger, R.W.W., 2009. SSPX: A program to compute strain from displacement/velocity data. Comput. Geosci. 35, 1343-1357, doi: 10.1016/j.cageo.2008.05.008.

Dach, R., Hugentobler, U., Fridez, P., Meindl, M., 2007. Bernese GPS software version 5.0. Astron. Institute, Univ. Bern 640.

Devoti, R., Esposito, A., Pietrantonio, G., Pisani, A.R., Riguzzi, F., 2011. Evidence of large scale deformation patterns from GPS data in the Italian subduction boundary. Earth Planet. Sci. Lett. 311, 230-241, doi: 10.1016/j.epsl.2011.09.034.

Devoti, R., Riguzzi, F., Cuffaro, M., Doglioni, C., 2008. New GPS constraints on the kinematics of the Apennines subduction. Earth Planet. Sci. Lett. 273, 163-174.

Dietrich, R., Dach, R., Engelhardt, G., Ihde, J., Korth, W., Kutterer, H.J., Lindner, K., Mayer, M., Menge, F., Miller, H., Müller, C., Niemeier, W., Perlt, J., Pohl, M., Salbach, H., Schenke, H.-W., Schöne, T., Seeber, G., Veit, A., Völksen, C., 2001. ITRF coordinates and plate velocities from 
repeated GPS campaigns in Antarctica - an analysis based on different individual solutions. J. Geod. 74, 756-766, doi: 10.1007/s001900000147.

Dow, J.M., Neilan, R.E., Rizos, C., 2009. The International GNSS Service in a changing landscape of Global Navigation Satellite Systems. J. Geod. 83, 689-689, doi: 10.1007/s00190009-0315-4.

Echeverria, A., Khazaradze, G., Asensio, E., Gárate, J., Dávila, J.M., Suriñach, E., Martín Dávila, J., 2013. Crustal deformation in eastern Betics from CuaTeNeo GPS network. Tectonophysics 608, 600-612, doi: http://dx.doi.org/10.1016/j.tecto.2013.08.020.

EPOS - European Plate Observing System website: www.epos-eu.org. Date Accessed: March 05, 2014

Estey, L.H., Meertens, C.M., 1999. TEQC: The Multi-Purpose Toolkit for GPS/GLONASS Data. GPS Solut. 3, 42-49.

Fadil, A., Vernant, P., McClusky, S., Reilinger, R., Gomez, F., Sari, D.B., Mourabit, T., Feigl, K., Barazangi, M., Ben Sari, D., 2006. Active tectonics of the western Mediterranean: Geodetic evidence for rollback of a delaminated subcontinental lithospheric slab beneath the Rif Mountains, Morocco. Geology 34, 529-532, doi: 10.1130/G22291.1.

Frontera, T., Concha, A., Blanco, P., Echeverria, A., Goula, X., Arbiol, R., Khazaradze, G., Pérez, F., Suriñach, E., 2012. DInSAR Coseismic Deformation of the May 2011Mw 5.1 Lorca Earthquake (southeastern Spain). Solid Earth 3, 111-119, doi: 10.5194/se-3-111-2012.

Herring, T., 2003. MATLAB Tools for viewing GPS velocities and time series. GPS Solut. 7, 194-199, doi: 10.1007/s10291-003-0068-0.

Herring, T.A., King, R.W., McClusky, S.C., 2010. Introduction to GAMIT/GLOBK. Mass. Inst. Technol., Cambridge, Mass.

Johnson, H.O., Agnew, D.C., 1995. Monument motion and measurements of crustal velocities. Geophys. Res. Lett. 22, 2905-2908, doi: 10.1029/95GL02661.

Kierulf, H.P., Plag, H.P., Bingley, R.M., Teferle, N., Demir, C., Cingoz, A., Yildiz, H., Garate, J., Davila, J.M., Silva, C.G., Zdunek, R., Jaworski, L., Martinez-Benjamin, J.J., Orus, R., Aragon, A., 2008. Comparison of GPS analysis strategies for high-accuracy vertical land motion. Phys. Chem. Earth 33, 194-204, doi: 10.1016/j.pce.2006.11.003.

King, M., Edwards, S., Clarke, P.J., 2002. Precise point positioning: Breaking the monopoly of relative GPS processing. Eng. Surv. Showc. 40-41.

Mao, A., Harrison, C.G.A., Dixon, T.H., 1999. Noise in GPS coordinate time series. J. Geophys. Res. 104, 2797, doi: 10.1029/1998JB900033.

Marín-Lechado, C., Galindo-Zaldívar, J., Gil, A.J., Borque, M.J., de Lacy, M.C., Pedrera, A., López-Garrido, A.C., Alfaro, P., García-Tortosa, F., Ramos, M.I., Rodríguez-Caderot, G., Rodríguez-Fernández, J., Ruiz-Constán, A., de Galdeano-Equiza, C.S., 2010. Levelling Profiles and a GPS Network to Monitor the Active Folding and Faulting Deformation in the Campo de Dalias (Betic Cordillera, Southeastern Spain). Sensors 10, 3504-3518, doi: 10.3390/s100403504. 
Martínez-Díaz, J.J., Bejar-Pizarro, M., Álvarez-Gómez, J.A., Mancilla, F.D.L., Stich, D., Herrera, G., Morales, J., 2012. Tectonic and seismic implications of an intersegment rupture. Tectonophysics 546-547, 28-37, doi: 10.1016/j.tecto.2012.04.010.

McClusky, S., Balassanian, S., Barka, A., Demir, C., Ergintav, S., Georgiev, I., Gurkan, O., Hamburger, M., Hurst, K., Kahle, H., Kastens, K., Kekelidze, G., King, R., Kotzev, V., Lenk, O., Mahmoud, S., Mishin, A., Nadariya, M., Ouzounis, A., Paradissis, D., Peter, Y., Prilepin, M., Reilinger, R., Sanli, I., Seeger, H., Tealeb, A., Toksoz, M.N., Veis, G., 2000. Global Positioning System constraints on plate kinematics and dynamics in the eastern Mediterranean and Caucasus. J. Geophys. Res. 105, 5695-5719, doi: 10.1029/1999JB900351.

McClusky, S., Reilinger, R., Mahmoud, S., Ben Sari, D., Tealeb, A., 2003. GPS constraints on Africa (Nubia) and Arabia plate motions. Geophys. J. Ineternational 155, 126-138, doi: 10.1046/j.1365-246X.2003.02023.x.

Palano, M., González, P.J., Fernández, J., 2013. Strain and stress fields along the Gibraltar Orogenic Arc: Constraints on active geodynamics. Gondwana Res. 23, 1071-1088, doi: 10.1016/j.gr.2012.05.021.

Pérez-Peña, A., Martín-Davila, J., Gárate, J., Berrocoso, M., Buforn, E., 2010. Velocity field and tectonic strain in Southern Spain and surrounding areas derived from GPS episodic measurements. J. Geodyn. 49, 232-240, doi: 10.1016/j.jog.2010.01.015.

Sanz de Galdeano, C., Buforn, E., 2005. From strike-slip to reverse reactivation: The Crevillente Fault System and seismicity in the Bullas-Mula area (Betic Cordillera, SE Spain). Geológica Acta $3,241-250$.

Scherneck, H.-G., 1991. A parametrized solid earth tide model and ocean tide loading effects for global geodetic baseline measurements. Geophys. J. Int. 106, 677-694, doi: 10.1111/j.1365246X.1991.tb06339.x.

Stich, D., Batlló, J., Morales, J., Macià, R., Dineva, S., Batllo, J., Macia, R., 2003. Source parameters of the MW=6.1 1910 Adra earthquake (southern Spain). Geophys. J. Int. 155, 539546, doi: 10.1046/j.1365-246X.2003.02059.x.

Wessel, P., Smith, W.H.F., Scharroo, R., Luis, J., Wobbe, F., 2013. Generic Mapping Tools: Improved Version Released. Eos, Trans. Am. Geophys. Union 94, 409-410, doi: $10.1002 / 2013 \mathrm{EO} 450001$.

Williams, S.D.P., Bock, Y., Fang, P., Jamason, P., Nikolaidis, R.M., Prawirodirdjo, L., Miller, M., Johnson, D.J., 2004. Error analysis of continuous GPS position time series. J. Geophys. Res. 109, B03412, doi: 10.1029/2003JB002741.

Zhang, J., Bock, Y., Johnson, H., Fang, P., Williams, S., Genrich, J., Wdowinski, S., Behr, J., 1997. Southern California permanent GPS geodetic array: Error analysis of daily position estimates and site velocities. J. Geophys. Res. 102, 18035, doi: 10.1029/97JB01380.

Zumberge, J.F., Heflin, M.B., Jefferson, D.C., Watkins, M.M., Webb, F.H., 1997. Precise point positioning for the efficient and robust analysis of GPS data from large networks. J. Geophys. Res. 102, 5005, doi: 10.1029/96JB03860. 
Supplementary Material
Click here to download attachment to manuscript: Annexes.pdf (1) f

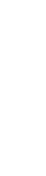

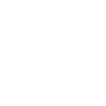

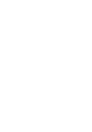

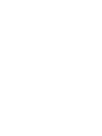
. .

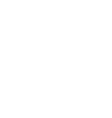

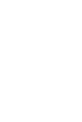

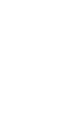

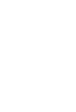

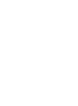

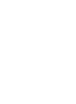

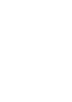

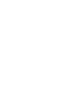
(

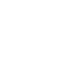
列

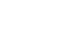

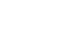

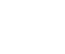

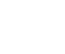

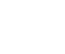

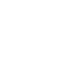
. . . . .

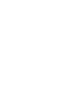
. . . . .

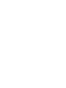

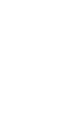
. . (1) 